University for Business and Technology in Kosovo

UBT Knowledge Center

UBT International Conference

2018 UBT International Conference

Oct 27th, 3:15 PM - 4:45 PM

\title{
Adaptation of Wood Processing Engineers to New Technologies
}

Ramadan Topuzi

University for Business and Technology, dan_topuzi@live.it

Arben Bejtja

Agricultural University of Tirana, arbenbejtja@yahoo.fr

Follow this and additional works at: https://knowledgecenter.ubt-uni.net/conference

Part of the Civil and Environmental Engineering Commons

\section{Recommended Citation}

Topuzi, Ramadan and Bejtja, Arben, "Adaptation of Wood Processing Engineers to New Technologies" (2018). UBT International Conference. 35.

https://knowledgecenter.ubt-uni.net/conference/2018/all-events/35

This Event is brought to you for free and open access by the Publication and Journals at UBT Knowledge Center. It has been accepted for inclusion in UBT International Conference by an authorized administrator of UBT Knowledge Center. For more information, please contact knowledge.center@ubt-uni.net. 


\title{
Adaptation of Wood Processing Engineers to New Technologies
}

\author{
Ramadan Topuzi ${ }^{1}$, Arben Bejtja ${ }^{2}$ \\ ${ }^{1}$ UBT - Higher Education Institution, Lagjja Kalabria 10000 p.n., Prishtinë- \\ Kosovo \\ ${ }^{2}$ Agricultural University of Tirana, Department of Wood Industry, Tirana-Albania \\ dan_topuzi@live.it, arbenbejtja@yahoo.fr
}

\begin{abstract}
New technologies have recently got a rapid and wide spread. They consist of softwares, systems and advanced engineering machinery, but not limited to these. In the furniture manufacturing industry they have found a wide application for their own specific nature. Wood Processing Engineers, given their university education, have a very important role applying their knowledge in the use of technologies. Today CAD CAM systems are becoming part of furniture design and manufacturing through digitally commanded machineries. The problem faced is the qualified staff for the use of these systems and machineries. This requires scientific preparation and training of specialists on the practical level. In Albania, market needs are met by Wood Processing Engineers and trained specialists. This study shows that graduates do not receive the appropriate professional training from the faculty. There is a lack of organic linkage; theoretical and scientific knowledge acquired in the faculty, with application in practice.
\end{abstract}

Keywords: wood processing engineers, new technologies.

\section{Introduction}

Wood Processing Engineers have been graduating for years from the Wood Industry Department at the Faculty of Forestry at the Agricultural University of Tirana. Graduates from this institution receive general scientific, engineering and technology knowledge, etc. The Faculty performs its mission through the training it provides to the student during the academic process, practices, up to his graduation. In Albania, the private sector provides real employment opportunitis for Wood Processing Engineers. This is the main labor market and should be the focus of the university to design the curricula to serve it. University Training of Engineers is seen by the labor market as a development and continuous progress potential, especially with regard to technology development. The university must precede this development or at least be in constant coherence with the scientific innovations. Today, the wood industry in Albania counts over 900 sustainable production entities and that produce and trade furniture and other wooden objects, with about 10,000 employees. Consequently, it constitutes a strong item of the labor market and of the economy.

The purpose of this study is to present a picture that combines the university training of Wood Processing Engineers with the needs of the labor market regarding the conception, adaptation and application of new technologies in the wood industry in Albania. 
The study is based on the analysis of a significant number of structured questionnaires for this purpose with data collected through face to face surveys. The sample used is the intentional (nonprobabilistic) sample.

A significant part of the engineers continue to contribute to the area they have studied. Engineers Result; employed, in leading positions and a good part of them are entrepreneurs. In the companies where they work they have primary tasks; the design and production of a number of constructive and ornamental elements needed for furniture production. In some powerful companies, the whole technological process is based on the massive use of new technologies. It starts with design through CAD software, continues with their carriage through CAM sites and application in $\mathrm{CNC}$ machineries. An increasing number of machines are produced and equipped with the most advanced techniques. Initially in Albania, there was an extensive use of the socalled pantographed techniques, working in three main movement directions (three axes) of the machinery spindle. Recently there have been spread those with five axes which are a perfection of technology in this direction, and which realize diverse profiles very fast and with high quality. This study further shows how Wood Processing Engineers approach this development, especially considering the training in practical terms also of the furniture production entities.

\section{Methodology}

The main basis of this study is; collecting data through questionnaires, through which the respondents express their opinion as regarding the Wood Processing Engineers.

Respondents have answered the question: In your opinion, do the Wood Processing Engineers adapt to the new technologies used? Answers have been provided through alternatives; Yes, No, Partly and I do not know. It has also been taken a verbal response through the auxiliary question: Do you have any comments about this?

The methodology followed for carrying out this study is:

- Evidencing the main entities operating in the field of wood processing in Albania;

- Drafting the necessary questionnaires for this purpose, through which the respondents give their assessment;

- $\quad$ Direct contact of respondents (Business managers / administrators, engineers, etc.) in the field (to Production Entities);

- Completing questionnaires through face-to-face interviewing;

- $\quad$ Processing and Analyzing Data.

\section{Data Collection}

For the conduct of the surveys, 270 main businesses have been selected throughout Albania. From the data collected for the wood industry in the field, it turns out that Wood Processing Engineers are an important factor in Albania. 56 engineers have been interviewed who have given their professional opinion about the new technologies. Also, the other respondents who are part of the same sector, have responded on this issue, and we think that their opinion should be considered. The occupations of the respondents are given in Table 1. 
Table 1. Occupations of respondents.

\begin{tabular}{rlcc}
\hline No. & Occupations of Respondents & $\begin{array}{c}\text { Number of } \\
\text { Answers }\end{array}$ & Expressed in \% \\
\hline 1 & Wood Processing Engineers & 56 & 20.74 \\
2 & Architects & 9 & 3.33 \\
3 & $\quad$ University Education & 98 & 36.30 \\
4 & Secondary Education & 107 & 39.63 \\
& TOTAL & 270 & 100.0 \\
\hline
\end{tabular}

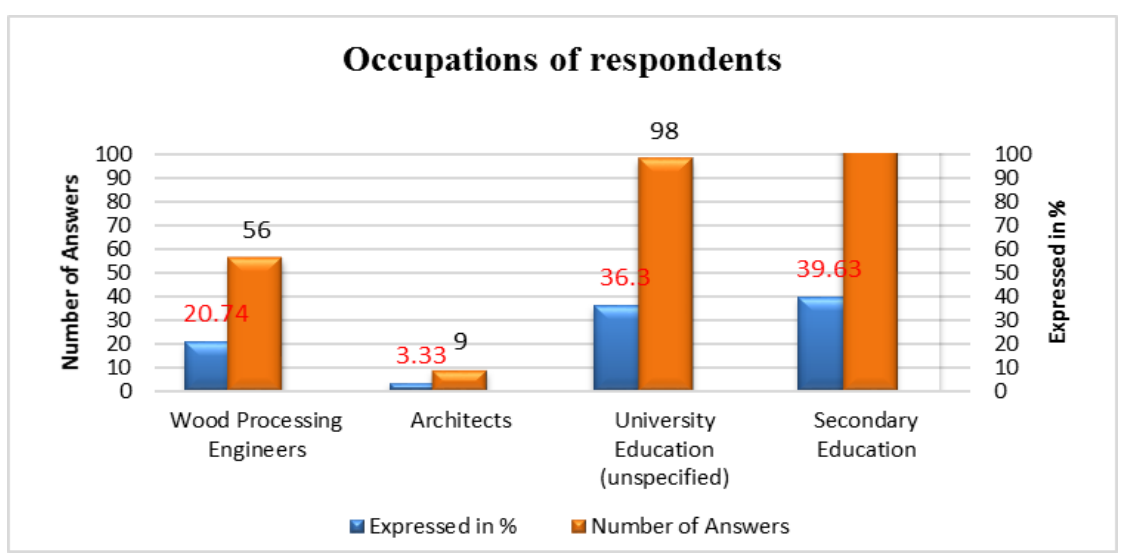

Figure 1. Occupations of respondents

\section{Analysis of data. Results}

Regarding the adaptation of Wood Processing Engineers with the new technologies used estimates are given in Table 2. 
Table 2. Adaptation of Wood Processing Engineers with the new technologies

\begin{tabular}{ccccc}
\hline Assessment & Yes & No & Partly & I do not know \\
\hline Number of Answers & 108 & 30 & 121 & 10 \\
Expressed in \% & 40 & 11.11 & 44.81 & 3.7 \\
\hline
\end{tabular}

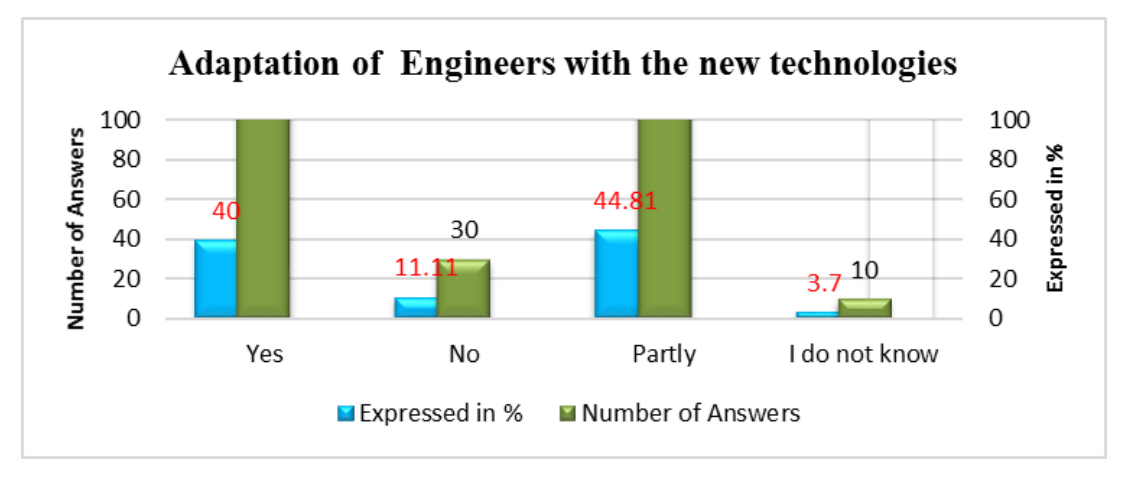

Figure 2. Adaptation of Wood Processing Engineers with the new technologies

As shown in table and figure 2, most respondents think that Wood Processing Engineers do not fit properly with the new technologies. There are about $11 \%$ of them who have said No. Meanwhile, $45 \%$ of the respondents say that Wood Processing Engineers fit partially. In this way we can reason that in total about $56 \%$ of the respondents have reservations about the training of engineers in terms of new technologies. Taking also some of the respondents who have answered; I do not know, they have hesitated to say No, this percentage is even higher. Only $40 \%$ of the respondents think positively.

Through the survey (following the question about new technologies) an answer was taken through the auxiliary question: Do you have any comments about this?

Answers were given in words (in text form) and were carefully analyzed by grouping the same and similar or similar answers. This highlighted a number of problems.

According to respondents, new technologies are not only mass applied in their companies, but, more and more, they are growing rapidly and becoming more and more advanced. Machinery and new technology lines require a qualified staff. The problem faced is the lack of qualified staff for the use of these systems and machineries. This requires scientific preparation and training of specialists on the practical level. According to the respondents, questions also arise for the theoretical and scientific training of graduates. They strive to link the rapid development of technology and the coherence of the university at least parallel to it. Respondents point to new technologies, CAD systems, CAMs, and technological machineries and lines that follow these systems. In Albania, market needs are met by Wood Processing Engineers and trained specialists. Trained specilists can not meet their needs because they lack basic theoretical knowledge or technological principles that can not be taught except in the University. We add here the fact that most of them are with secondary vocational education. Trainings that are held mainly by companies that bring machinery and technology lines but also individual vocational courses of specialists do not solve this problem. 
Respondents see the solution to engineers in general and to Wood Processing Engineers in particular. From the analysis of all the answers received it turns out that the main problem is the practicing of students in internships during the studies. Graduates conduct a 10-week internship; what is called professional practice, even at the end of it, they draft a report on the experience gained. The result of the survey shows that this is not only insufficient in time but also from the qualitative point of view, it is improperly conducted. The students develop their internship at the production entities, either on the basis of individual recognition or through the faculty and business agreements. As regards the practicing or development of students' internship, we have concluded that:

One of the possibilities is through paid employment, ie. that the student is hired or paid for the work done. A paid job is more motivating than an unpaid job. In general, there is a small category of those who think that the student should be interested and motivated with regard to studies and more in putting his knowledge gained into practice. But there are opinions that go against the idea of payment with the reasoning that the student is learning, I am helping him, I am creating him the opportunity to practice, use the machineries, technology, etc..

The analysis clearly shows a higher appreciation for the practice development through paid employment. This is assessed as the most effective method for the student. Respondents have had cases that have been expressed that this way the student becomes more responsible also in the use of machinery and raw materials. Of course payment is supposed to be symbolic and subject to production, work position and performance. For the way of organizing either in student groups or individually, there is no clear conclusion as the answers are very close.

\section{Another way of results interpretation.}

Another argument that justifies the necessity of engineers' training on new technologies are the opinions of respondents based on what a Wood Processing Engineer should know. Regarding the knowledge on new technologies, respondents note that they are indispensable. They have expressed reservations about the training of engineers in many different forms. Comments of respondents on field-related knowledge are diverse and grouped as follows:

A Wood Processing Engineer needs to be professionally qualified, which in the opinion of 39\% of respondents means:

- to have knowledge on wood and other wood-based materials, its physical and mechanical properties;

- wood machineries and mechanical processing lines used in Albania;

- the structure of its production, organization and management;

- knowledge and oversight of projects, budgeting and costs, etc.

A Wood Processing Engineer should have design skills (architecture and design) that in the opinion of $20 \%$ of the respondents means:

- to know the design area in general;

- be capable of conceiving and designing furniture and ornaments;

- to design or sketch their variety.

A Wood Processing Engineer should be more practically prepared (more practice), which in the opinion of $11 \%$ of respondents means:

- are not practically able or lack the appropriate applicable knowledge;

- there should be more professional practice in the curricula;

- should have experience from other countries; 
- there are also suggestions on the theory-practice sharing, 50\% theory and 50\% practice;

A Wood Processing Engineer needs to be able to use computer programs, which in the opinion of $10 \%$ of respondents means:

- to know well the computer programs such as microsoft office;

- to know mainly: CAD, CIM, 3D Max, etc.

A Wood Processing Engineer needs to be able to use new technologies, which in the opinion of $10 \%$ of respondents means:

- to know how to use new / modern technological lines;

- to have knowldge on machineries with digital commands;

A Wood Processing Engineer, in the opinion of $4 \%$ of respondents, should always have good communication skills, including:

- group communication;

- and communication with the client;

The rest of the respondents who have preferred to express themselves on this question have given different opinions as: foreign language knowledge about 3\% and not properly prepared $3 \%$. Summing up the opinions of the surveyed, we hereby conclude that:

Design and practice skills relate to new technologies. Computer programs are a necessity. By grouping these with the answers specifically given to new technologies, it turns out that most of the respondents or $51 \%$ of them maximally value the training of engineers with knowledge of new technologies. Respondents point out that Wood Processing Engineers graduating from the Faculty of Forestry do not fit properly with these technologies and the university has to do more with regard to the training of graduates especially in the internship field.

\section{Conclusions}

Respondents believe that Wood Processing Engineers graduating in the Wood Industry Department are not properly oriented towards the current labor market. Their responses express the demand for; knowledge of new technologies, design skills, computer software, professional skills, etc.

The results show that Wood Processing Engineers do not adapt properly to the new technologies. Respondents express themselves with reservations about engineers who only complete the first level of Bachelor studies. Internship should have a duration of more than 10 weeks that it currently has. It is evaluated as most effective for the student developing the practice through paid employment. The demand for excellence should not be considered as an utopia, but as a necessity to make it possible to adapt to technological innovations.

\section{Recommendations}

Academic curriculums should be designed in accordance with the development of scientific and technological knowledge and in accordance with all new teaching methodologies. They must be flexible and provide the necessary competences for business and economy needs. Teaching 
methods should ensure the acquisition of new information and its transmission in the most attractive way. The organization of the curriculum and its content should be adapted to technological and scientific developments. If we do not anticipate the development, the least that needs to be done is to move parallel to it. We must think of changing the concept of internship with the aim of carrying out the practice with concrete themes in the field and strengthen links with businesses.

\section{References}

1. Research Design: Qualitative, quantitative, and mixed medhods approaches, Second edition-John W. Creswell, 2003

2. Engineering Education Elements and their Assessment by the Labor Market. Topuzi R, Bejtja A, Peri L.

3. Evoluation of the curriculum of the Wood Industry in Department in view of the Wood Processing Engineers who perform this activity. Topuzi R, Bejtja A, Peri L.

4. Distribution of Wood Processing Industry in Albania. Topuzi R, Bejtja A, Peri L.

5. Human Resource Management in Public Higher Education in the Tempus Partner Countries, Issue 10 - June 2012 